Arq. Bras. Med. Vet. Zootec., v.70, n.5, p.1483-1488, 2018

\title{
Sondagem da pelve renal guiada por cistoscopia em éguas
}

\author{
[Catheterization of the renal pelvis guided by cistoscopy in mares] \\ L. Strugava ${ }^{1}$, L.P.T.C. Dornbusch ${ }^{2}$, J.R.Silva-Meirelles ${ }^{2}$, M.L. Castro ${ }^{2}$, E.M. Busato ${ }^{2}$, \\ Y.N.M. Silva ${ }^{1}$, C. Souza ${ }^{3}$, I.R.B. Filho ${ }^{3}$, R.L.Guedes ${ }^{2}$, P.T. Dornbusch ${ }^{3}$ \\ ${ }^{1}$ Aluna de graduação - Universidade Federal do Paraná - Curitiba, PR \\ ${ }^{2}$ Aluno de pós-graduação - Universidade Federal do Paraná - Curitiba, PR \\ ${ }^{3}$ Universidade Federal do Paraná - Curitiba, PR
}

\begin{abstract}
RESUMO
O objetivo deste trabalho foi padronizar a técnica de acesso à pelve renal por meio de sondagem ureteral guiada por cistoscopia em éguas. Foram utilizados oito animais, de raças variadas, com peso médio de $439 \mathrm{~kg}$. As éguas foram sedadas e mantidas em tronco de contenção para a realização da cistoscopia com endoscópio flexível. Após identificação do óstio ureteral esquerdo, uma sonda de polietileno foi introduzida em seu lume, até a pelve renal. A localização da sonda no rim foi confirmada por meio de ultrassonografia transcutânea. Foram coletados $3 \mathrm{~mL}$ de urina, de forma asséptica, para citologia e cultura bacteriana. Todas as amostras obtiveram resultados negativos na cultura e análise do sedimento urinário. Nenhum dos animais apresentou quaisquer complicações após a sondagem. Este estudo demonstrou que a coleta de urina diretamente da pelve renal em éguas, com auxílio da cistoscopia na realização da sondagem ureteral, consiste em um procedimento viável e seguro.
\end{abstract}

Palavras-chave: endoscopia, pielonefrite, cavalos, trato urinário

\begin{abstract}
The objective of this study was to standardize the technique of access to the renal pelvis by means of ureteral catheterization guided by cystoscopy in mares. Eight animals of different races were used, with an average weight of $439 \mathrm{~kg}$. The mares were sedated and contained in containment trunk for the accomplishment of cystoscopy with flexible endoscope. After the identification of the left ureteral ostium, from where inside a catheter was introduced, which went through the entire extension of the ureter up to the renal pelvis. After identification of the left ureteral ostium, from where inside a catheter was introduced, into its lumen until reaching the renal pelvis. The location of the probe in the kidney was confirmed by transcutaneous ultrasonography. Three $\mathrm{ml}$ of urine was aspirated aseptically for cytology and microbiological culture. All the samples obtained negative results in the culture and sedimentation. None of the animals had any complications after catheterization. This study demonstrated that the collection of urine directly from the renal pelvis in mares, with the assistance of cystoscopy in the realization of the ureteral catheter, consists of a viable and safe procedure.
\end{abstract}

Keywords: endoscopy, pyelonephritis, horses, urinary tract

\section{INTRODUÇÃO}

O sistema urinário dos equinos consiste de dois rins, dois ureteres, uma bexiga e uma uretra. $\mathrm{O}$ rim direito localiza-se abaixo da extensão dorsal das duas ou três últimas costelas e do primeiro processo transverso lombar, mede

Recebido em 8 de junho de 2017

Aceito em 16 de dezembro de 2017

E-mail: lucimarastrugava@gmail.com aproximadamente $15 \mathrm{~cm}$ de comprimento, $15 \mathrm{~cm}$ de largura e 5-6cm de altura. Quando comparado ao rim esquerdo, localiza-se mais cranialmente, $o$ que impossibilita sua palpação via retal. O rim esquerdo tem, em média, $18 \mathrm{~cm}$ de comprimento, $10-12 \mathrm{~cm}$ de largura e $2-6 \mathrm{~cm}$ de altura, localiza-se caudalmente à última costela e sua face caudoventral pode ser palpada via retal. Os 
ureteres têm de 6 a $8 \mathrm{~mm}$ de diâmetro e seguem um trajeto de aproximadamente $70 \mathrm{~cm}$ a partir dos rins até o trígono da bexiga, onde se inserem próximos à uretra (Schoot, 2000). Em éguas, a uretra mede de 5 a $7,5 \mathrm{~cm}$ de comprimento (Carvalho, 2008).

As infecções bacterianas que acometem o trato urinário dos equinos são pouco frequentes na rotina clínica, entretanto, quando ocorrem, as infecções ascendentes possuem maior prevalência, sendo as éguas mais acometidas que os cavalos por apresentarem a uretra mais curta. Dentre as infecções, destacam-se uretrite, cistite e pielonefrite, sendo esta a mais frequente. As bactérias mais comumente envolvidas na pielonefrite são: Escherichia coli, Proteus spp., Klebsiella spp., Staphylococcus spp., Streptococcus spp. e Pseudomonas (Confer e Panciera, 1998).

Nos bovinos e equinos, o sistema urinário pode ser avaliado por meio de exame clínico e exames complementares, como urinálise, exame bacteriológico, citológico, radiográfico e ultrassonográfico. Os procedimentos endoscópicos também já estão descritos em grandes animais, porém seu uso até o momento se restringe ao trato urinário inferior, ou seja, uretra e bexiga (Stockham e Scott, 2011).

A endoscopia tem sido utilizada com sucesso para diagnóstico e tratamento de enfermidades do trato urinário superior de humanos (Cocuzza et al., 2008). Na medicina veterinária, a cistoscopia tem sido realizada em cavalos desde o ano de 1970, com a finalidade de examinar o sistema urinário inferior, permitindo a exploração visual do interior da bexiga e da uretra, bem como a realização de biópsias (Pasquel et al., 2013). A cistoscopia é indicada em casos de cistite crônica, hematúria, tenesmo, polaciúria, incontinência urinária, alteração do fluxo urinário, traumas e cálculos (McCarthy e McDermaid, 1990).

O exame bacteriológico e a análise do sedimento da urina são métodos que auxiliam o diagnóstico de infecções no trato urinário (Lopes et al., 2007; Schumacher e Moll, 2007). O procedimento para coleta de urina da pelve renal já foi descrito em humanos (Cocuzza et al., 2008) e cães (Defarges et al., 2013). Existem poucos dados na literatura sobre tal método de coleta em equinos, e não há padronização da técnica para a realização nessa espécie. Pasquel et al. (2013), em estudo cadavérico, descreveram o acesso à pelve renal de éguas e Tomlinson et al. (2001) relataram a sondagem ureteral em um caso de ureter ectópico desembocando na vagina. Tendo em vista a escassez de dados sobre o tema, o objetivo deste trabalho foi padronizar a técnica de acesso à pelve renal, por meio de sondagem ureteral guiada por cistoscopia, em éguas.

\section{MATERIAL E MÉTODOS}

Este trabalho foi realizado no Setor de Grandes Animais do Hospital Veterinário da Universidade Federal do Paraná - UFPR, após aprovação pelo Comitê de Ética para o Uso de Animais (Ceua/UFPR), sob registro no 036/2015. Foram utilizadas oito éguas hígidas, de diferentes raças (sendo duas Puro Sangue Inglês e seis sem raça definida), com idade entre três e oito anos e peso variando de 350 a $545 \mathrm{~kg}$. Previamente ao experimento, os animais foram submetidos a jejum alimentar de 12 horas e jejum hídrico de seis horas. Para a realização do procedimento, foram contidos em tronco específico para a espécie, onde se realizou tricotomia de aproximadamente $15 \mathrm{~cm}^{2}$ na região toracolombar, entre o $16^{\circ}$ espaço intercostal (EIC) esquerdo e a fossa paralombar, para posterior realização de ultrassonografia. A cauda dos animais foi enfaixada, a genitália externa e a região perianal foram higienizadas com água corrente e, em seguida, secas com toalha de papel. O esvaziamento da bexiga foi realizado por meio de sondagem uretral com sonda $\mathrm{n}^{\mathrm{o}} 20$.

$\mathrm{Na}$ sequência, as éguas foram sedadas com xilazina, na dose de $1 \mathrm{mg} / \mathrm{kg}$, administrada por via intravenosa (IV). Após 15 minutos, foi introduzido, pelo óstio uretral externo, um endoscópio flexível com diâmetro de $5 \mathrm{~mm}$ e comprimento de $100 \mathrm{~cm}$ (modelo Karl Storz, 60001VL1), esterilizado em óxido de etileno. Uma vez inspecionada a uretra (Fig. 1A) e a bexiga (Fig. 1B), realizou-se insuflação desta com ar comprimido para permitir a identificação dos óstios ureterais, os quais apresentavam escoamento de urina. Pelo canal de trabalho do endoscópio, foi introduzida, no óstio ureteral esquerdo, em sentido retrógrado até a pelve renal, uma sonda de polietileno estéril com ponta metálica atraumática (Fig. 1C), tendo dois metros de comprimento. Ao atingir a pelve renal, a 
ponta metálica da sonda foi identificada por ultrassonografia transcutânea (Fig. 1D) (ultrassom marca Ultrasonix, modelo EizoFlexscan, L568), realizada com transdutor convexo de frequência $5 \mathrm{MHz}$. Uma seringa de $10 \mathrm{~mL}$, estéril, foi acoplada, de forma asséptica, à extremidade livre da sonda para aspiração de urina. Nas oito éguas, foi acessada a pelve renal esquerda e, em duas, também a direita, sendo essa manobra realizada apenas para verificar se a sonda progredia de forma satisfatória em ambos os ureteres.

Das amostras de urina coletadas, uma alíquota com 10 microlitros foi enviada ao Laboratório de Microbiologia da Universidade Federal do Paraná, onde foi semeada em placa de ágar sangue e incubada em estufa a $37^{\circ} \mathrm{C}$, por 24 horas. Após esse período, realizou-se a leitura das placas. Uma segunda alíquota, com dois mililitros de urina, foi processada em citocentrífuga (Novatecnia NT 800), a 5000 rotações por minuto, durante cinco minutos, para observar se havia a formação de sedimento e proceder à análise dele, quando presente.

\section{RESULTADOS E DISCUSSÃO}

Nos equinos adultos, a coleta de urina é limitada à micção espontânea e cateterização da bexiga, via sondagem uretral. A cistocentese não pode ser realizada, devido ao tamanho do animal e à posição da bexiga. Em ambas as técnicas, principalmente na micção espontânea, existe a possibilidade de contaminação da amostra (Schott et al., 1990; MacLeay e Kohn, 1998), o que pode gerar resultados falso-positivos na cultura. A coleta asséptica de urina da pelve renal, como realizada neste trabalho, representa uma ferramenta importante no diagnóstico de pielonefrite, por permitir amostras representativas e sem contaminações.

Existem poucos relatos de sondagem ureteral em éguas na literatura. Pasquel et al. (2013) realizaram um estudo cadavérico que descrevia o acesso à pelve renal de 10 equinos. Nesse trabalho, os rins das éguas foram retirados para permitir a introdução do endoscópio na pelve renal, a qual foi distendida com injeção de 35 a $45 \mathrm{~mL}$ de formalina, posto que volumes maiores causaram ruptura do parênquima renal. Apesar das dificuldades descritas pelos autores, eles conseguiram acessar a pelve, podendo observar a estrutura e a anatomia por meio da endoscopia. Schott et al. (1990) realizaram coleta de urina ureteral mediante a introdução de cateter nos ureteres (progredindo cerca de 5 a $10 \mathrm{~cm}$, apenas). Procedeu-se à cateterização com auxílio de cistoscopia, no entanto a pelve renal não foi acessada. Segundo estes autores, a sondagem ureteral é uma forma de diagnosticar desordem unilateral no trato urinário.

Tomlinson et al. (2001) relataram o caso de uma potra de três meses, que apresentava escoamento contínuo de urina pela vulva. Durante endoscopia, foi identificado e cateterizado um ureter ectópico localizado na vagina. Os autores coletaram urina diretamente da pelve renal por punção transcutânea, guiada por ultrassonografia. No presente trabalho, o acesso à pelve foi realizado por sondagem ureteral, sendo utilizada ultrassonografia renal transcutânea durante $\mathrm{o}$ procedimento para a identificação da ponta metálica da sonda, alojada na pelve renal, confirmando a localização dela. Vale ressaltar que a ultrassonografia renal é uma importante ferramenta para verificar a estrutura dos rins, realizar o diagnóstico de cálculos e de outras alterações estruturais e circulatórias desse órgão (Thomassian, 2005). Quando se trata de cálculos, observa-se presença de formações ecogênicas formando sombra acústica posterior, o que sugere urólitos (Calciolari et al., 2016). As concreções formadas podem se apresentar na forma ovoide, esferoidal ou multifacetada, e a formação dessas depende de condições predisponentes, como presença ou formação de uma matriz ou núcleo de deposição (Thomassian, 2005). Os animais utilizados neste projeto não apresentaram alterações renais à ultrassonografia.

A sondagem do ureter esquerdo foi possível em todas as éguas e a progressão da sonda ocorreu sem resistência até a pelve renal, onde foram coletadas amostras de urina (Fig. 1E e 1F). A escolha do ureter esquerdo deu-se pela posição anatômica do rim esquerdo, que é mais caudal quando comparado ao direito, proporcionando um melhor acesso à pelve renal. Em duas éguas, foi possível acessar também a pelve do rim direito. Na leitura das placas de ágar sangue em que se realizou a cultura das amostras, não foi detectado crescimento bacteriano. O resumo dos resultados pode ser visualizado na Tab. 1 . 

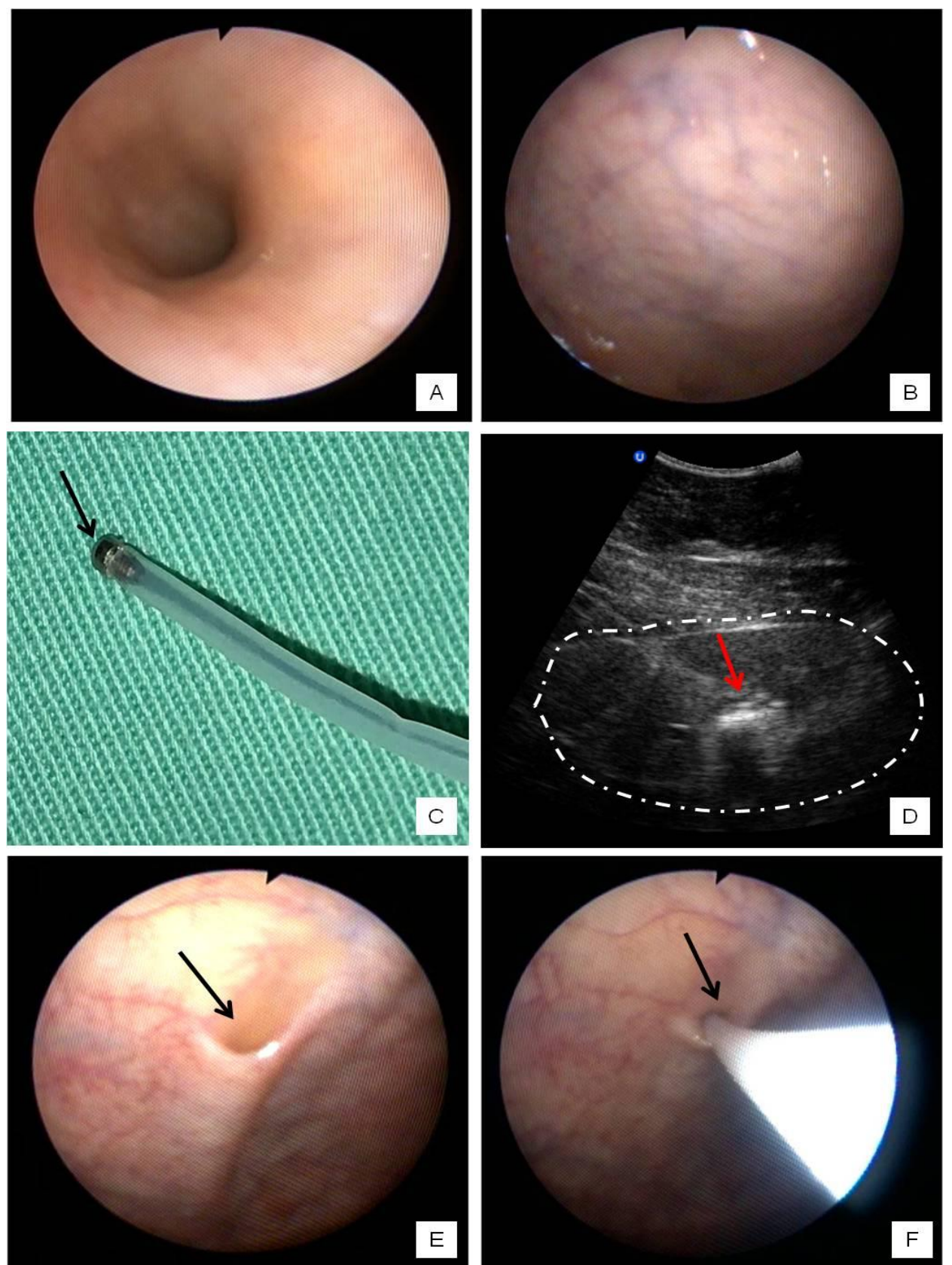

Figura 1. Imagens relativas ao procedimento de sondagem ureteral com acesso à pelve renal de éguas. A: visualização da uretra; B: bexiga; C: sonda de polietileno estéril com ponta metálica atraumática (seta); D: visualização da ponta metálica da sonda alojada na pelve renal (seta), por meio de ultrassonografia transcutânea; E: óstio ureteral esquerdo com escoamento de urina (seta); F: introdução da sonda de polietileno estéril com ponta metálica atraumática pelo óstio ureteral esquerdo. 
Tabela 1. Resultados das análises de sedimento (citologia) e cultura bacteriana da urina coletada da pelve renal de oito éguas hígidas

\begin{tabular}{ccccccccc} 
Animal & 1 & 2 & 3 & 4 & 5 & 6 & 7 & 8 \\
\hline Peso & 390 & 545 & 350 & 481 & 500 & 400 & 501 & 350 \\
Raça & SRD & PSI & SRD & SRD & SRD & SRD & PSI & SRD \\
Idade-anos & 15 & 15 & 8 & 10 & 10 & 3 & 14 & 8 \\
Sedimento & Neg. & Neg. & Neg. & Neg. & Neg. & Neg. & Neg. & Neg. \\
Cultura & Neg. & Neg. & Neg. & Neg. & Neg. & Neg. & Neg. & Neg. \\
\hline
\end{tabular}

*SRD: sem raça definida.

*PSI: Puro Sangue Inglês.

*Neg: negativo.

Korets et al. (2011), ao realizarem um estudo em humanos com nefrolitíase, compararam amostras de urina coletadas da bexiga com as da pelve renal para a realização de cultura bacteriana. De acordo com esses autores, a cultura da urina pélvica é a forma mais precisa para diagnosticar a infecção renal. Nos animais do presente trabalho, todas as culturas foram negativas para crescimento bacteriano, o que era esperado, visto que os animais eram hígidos. Esse resultado também comprova que a técnica foi asséptica, não havendo contaminação da amostra, ocorrência comum em outros métodos de coleta.

As análises de sedimento obtiveram resultados negativos, com ausência de hemácias e leucócitos nas amostras avaliadas. Ao se realizar o exame do sedimento urinário em grandes animais, é esperado encontrar leucócitos e hemácias em um número máximo de cinco células por campo; números superiores sugerem inflamação do trato urinário (Carlson, 2006). Inflamação de tecidos, da mucosa, da submucosa ou do parênquima renal faz com que os neutrófilos e os monócitos presentes no sangue migrem para a urina, podendo, assim, ser visualizados na microscopia (Araújo et al., 2009). A ausência dessas células nas amostras analisadas sugere a inexistência de moléstias no trato urinário das éguas deste estudo, porém não foram encontrados valores de referência na literatura consultada a respeito da citologia de urina obtida da pelve renal de pacientes saudáveis, em nenhuma espécie. Quando há hematúria, com mais de cinco hemácias por campo no sedimento, deve-se considerar a possibilidade de hemorragia patológica, oriunda de lesão vascular causada por traumatismos, infartos renais ou, ainda, por hemorragia iatrogênica devido à sondagem (Stockham e Scott, 2011). Não foi detectada presença de hemácias em nenhuma amostra, indicando que o trauma tecidual da migração da sonda de coleta foi mínimo.

A principal dificuldade encontrada no presente estudo foi relativa ao tamanho do endoscópio utilizado, que possuía 100 centímetros de comprimento, sendo necessário utilizar toda extensão do equipamento para acessar a pelve renal nas éguas maiores. Não foram observadas complicações ou sinais de desconforto durante ou após o procedimento em nenhum dos animais.

\section{CONCLUSÃO}

No presente estudo, foi possível demonstrar que a sondagem ureteral retrógrada, guiada por cistoscopia, para coleta de urina diretamente da pelve renal foi viável e não causou complicações aos animais. Dessa forma, a técnica pode ser empregada como auxílio diagnóstico em afecções do sistema urinário superior.

\section{REFERÊNCIAS}

ARAÚJO, P.B.; PEREIRA, D.S.; TEIXEIRA, M.N. et al. Urinálise como instrumento auxiliar no diagnóstico de enfermidades em pequenos ruminantes. Med. Vet., v.3, p.30-38, 2009.

CALCIOLARI, K.; GRAVENA, K.; CEREJO, S.A. et al. Relato de caso clínica: cirurgia de grandes animais - urolitíase uretral obstrutiva em equino macho. Investigação, v.15, p.46-50, 2016. 
CARLSON, G.P. Testes bioquímicos. In: SMITH, B.O. Medicina interna de grandes animais. 3.ed. São Paulo: Manoele, 2006. p.389412.

CARVALHO, M.B. Semiologia do sistema urinário. In: FEITOSA, F.D. Semiologia veterinária: a arte do diagnóstico. 2.ed. São Paulo: Roca, 2008. p.427-448.

COCUZZA, M.; COLOMBO, J.R.; COCUZZA, A.L. et al. Outcomes of flexible ureteroscopic lithotripsy with holmium laser for upper urinary tract calculi. Int. Braz. J. Urol., v.34, p.143-150, 2008.

CONFER, A.W.; PANCIERA, R.J. Sistema urinário. In: CARLTON, W.W.; McGAVIN, M.D. Patologia veterinária especial de Thomson. 2.ed. Porto Alegre: Artmed. 1998. p.228-265.

DEFARGES, A.; BERENT, A.; DUNN, M. New alternatives of minimally invasive management of uroliths: ureteroliths. Comp. Cont. Educ. Vet., v.35, p.1-7, 2013.

KORETS, R.; GRAVERSEN, J.A.; KATES, M. et al. Post-percutaneous nephrolithotomy systemic inflammatory response: a prospective analysis of preoperative urine, renal pelvic urine and stone cultures. J. Urol., v.186, p.1899-1903, 2011.

LOPES, S.T.A.; BIONDO, A.W.; SANTOS, A.P. Manual de patologia clínica veterinária. 3.ed. Santa Maria: UFSM/Departamento de Clínica de Pequenos Animais, 2007. 107p.
MacLEAY. J.M.; KOHN, C.W. Results of quantitative cultures of urine by free catch and catheterization from healthy adult horses. J. Vet. Intern. Med., v.12, p.76-78, 1998.

McCARTHY, T.C.; McDERMAID, S.L. Cistoscopy. Vet. Clin. N. Am. Small. Anim. Pract., v.20, p.1315-1339, 1990.

PASQUEL, S.G.; AGNEW, D.; NELSON, N. et al. Ureteropyeloscopic anatomy of the renal pelvis of the horse. Equine Vet. J., v.45, p.31-38, 2013.

SCHOTT, H.C. O sistema urinário. In: REED, S.M; BAYLY, W.M. Medicina interna equina. 1.ed. Rio de Janeiro: Guanabara Koogan, 2000. p.693-701.

SCHOTT, H.C.; HODGSON, D.R.; BAYLY, W.M. Ureteral catheterisation in the horse. Equine Vet. Educ. v.2, p.140-143, 1990.

SCHUMACHER, J.; MOLL, H.D. Manual de procedimentos diagnósticos em equinos. 1ed. São Paulo: Roca. 2007, 180p.

STOCKHAM, S.L.; SCOTT, M.A. Fundamentos da patologia clínica veterinária. 2.ed. Rio de Janeiro: Guanabara Koogan. 2011. 744p.

THOMASSIAN, A.E. Enfermidades dos cavalos. 4.ed. São Paulo: Livraria Varela, 2005. $574 \mathrm{p}$.

TOMLINSON, J.E.; FARNSWORTH, K.; SAGE, A.B. et al. Percutaneous ultrasound guided pyelography aided diagnosis of ectopic ureter and hydronephrosis in a 3 week old filly. Vet. Radiol. Ultrasound, v.42, p.349-351, 2001. 